\title{
Stimulation of polyketide metabolism in Streptomyces fradiae by tylosin and its glycosylated precursors
}

\author{
Steven A. Fish† and Eric Cundliffe \\ Author for correspondence: Eric Cundliffe. Tel: +44 116252 3451. Fax: +44 1162523369. \\ e-mail : ec13@le.ac.uk
}

Department of Biochemistry, University of Leicester, Leicester LE1 7RH, UK
Three glycosyltransferases are involved in tylosin biosynthesis in Streptomyces fradiae. The first sugar to be added to the polyketide aglycone (tylactone) is mycaminose and the gene encoding mycaminosyltransferase is orf2* (tylM2). However, targeted disruption of orf2* did not lead to the accumulation of tylactone under conditions that normally favour tylosin production; instead, the synthesis of tylactone was virtually abolished. This may, in part, have resulted from a polar effect on the expression of genes downstream of orf2*, particularly orf4* (ccr) which encodes crotonyl-CoA reductase, an enzyme that supplies 4-carbon extender units for polyketide metabolism. However, that cannot be the entire explanation, since tylosin production was restored at about $10 \%$ of the wild-type level when orf $2 *$ was re-introduced into the disrupted strain. When glycosylated precursors of tylosin were fed to the disrupted strain, they were converted to tylosin, confirming that two of the three glycosyltransferase activities associated with tylosin biosynthesis were still intact. Interestingly, however, tylactone also accumulated under such conditions and, to a much lesser extent, when tylosin was added to similar fermentations. It is concluded that glycosylated macrolides exert a pronounced positive effect on polyketide metabolism in 5 . fradiae.

Keywords: tylosin production, glycosyltransferase, polyketide metabolism, Streptomyces fradiae

\section{INTRODUCTION}

The macrolide antibiotic, tylosin (Fig. 1), is produced by Streptomyces fradiae via a combination of polyketide and 6-deoxyhexose metabolism. Glycosylation of tylactone, the cyclized polyketide product, always begins with the addition of mycaminose followed, in a preferred but not obligatory order, by deoxyallose and then mycarose to generate demethyl-macrocin. Stepwise bis $\mathrm{O}$-methylation then converts the deoxyallose moiety to mycinose as macrocin is produced and converted to tylosin (Baltz et al., 1983). Characterization of the tylosin biosynthetic pathway (Fig. 2) was facilitated by the availability of non-producing mutants of $S$. fradiae, generated using NTG (Baltz \& Seno, 1981). Collectively, these exhibited nine distinct phenotypes in cross-feeding

Abbreviations: OMT, O-mycaminosyl-tylonolide; DMT, demycinosyltylosin.

†Present address: Department of Microbiology and Immunology, University of Leicester, Leicester LE1 7RH, UK. experiments and allowed 13 genetic loci $(t y l A-M)$ to be mapped (Fig. 3) following complementation studies using cloned fragments of $t y l$ DNA (Beckmann $e t$ al.,
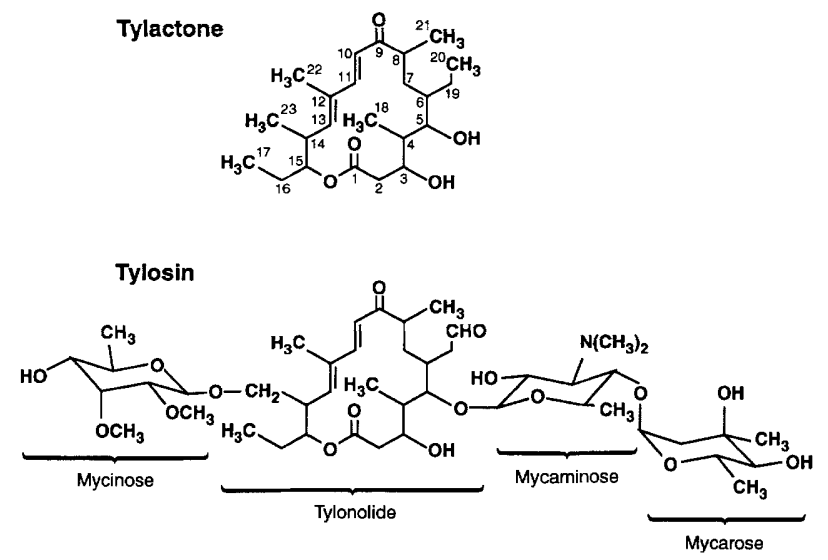

Fig. 1. Structures of tylactone and tylosin. 


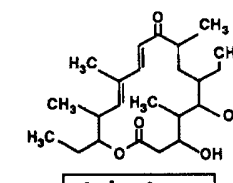

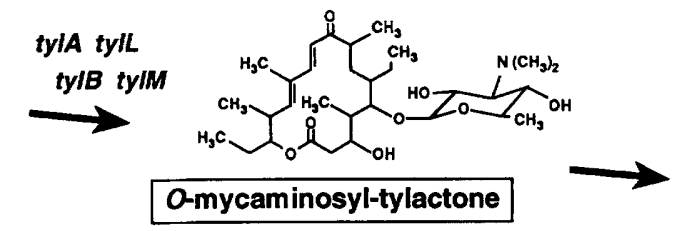

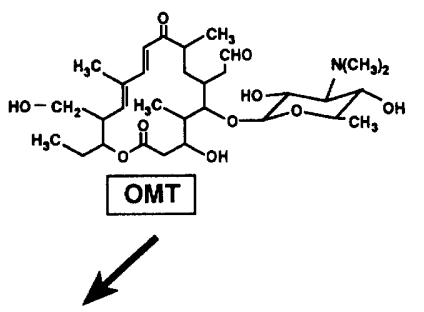

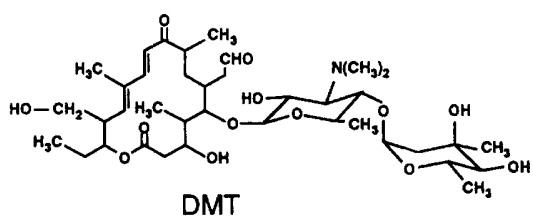<smiles>CCC</smiles>

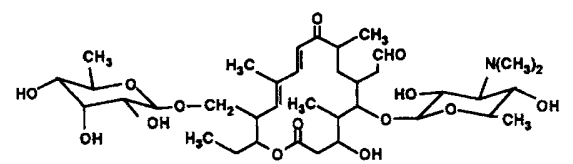

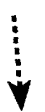

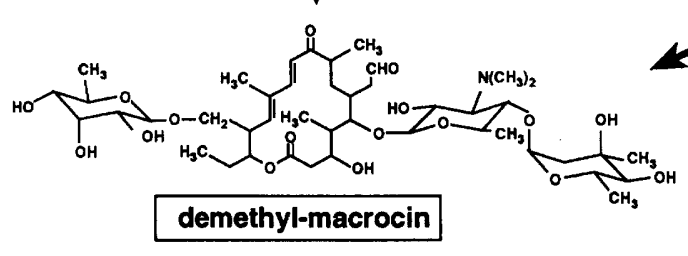

demethyl-lactenocin
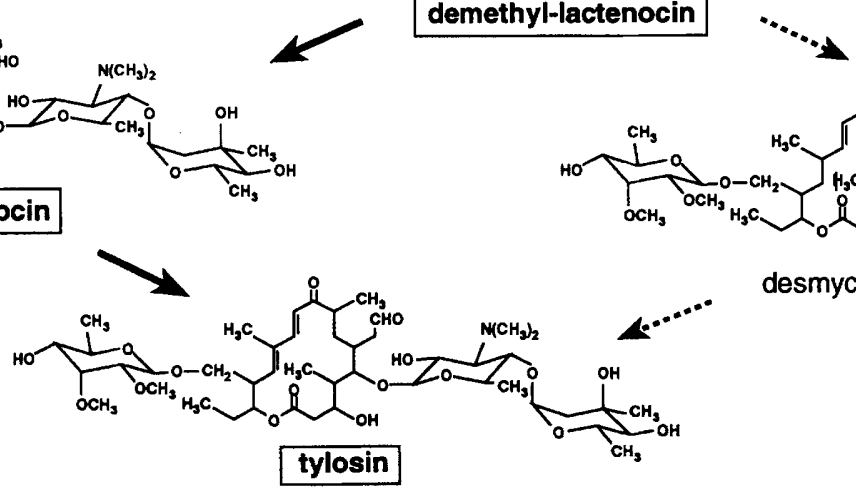

desmycosin

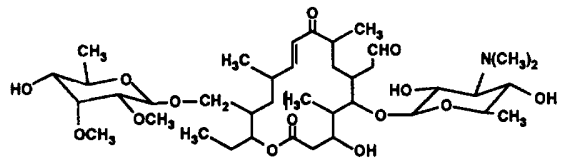

Fig. 2. The biosynthetic route from tylactone to tylosin. The preferred pathway from OMT to tylosin (solid arrows) goes via demethyl-lactenocin and demethyl-macrocin (Baltz et al., 1983). However, this route is not obligatory since DMT and desmycosin accumulate in blocked mutants of $S$. fradiae and can be bioconverted to tylosin (dashed arrows). The step at which various tyl mutations block the pathway is indicated.

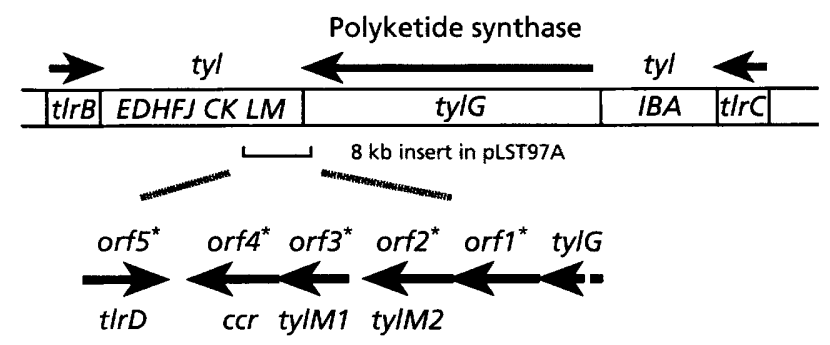

Fig. 3. The tylosin biosynthetic gene cluster of Streptomyces fradiae.

1989; Fishman et al., 1987). Sequence analysis of DNA spanning the tylLM loci (Gandecha et al., 1997) revealed four ORFs (orf $1^{*}-4^{*}$ ) located between the terminal thioesterase gene of the $t y l G$ polyketide synthase cluster and the resistance determinant, $\operatorname{tr} D$ (Fig. 3). The function of the Orf1* protein is not known, but the deduced products of the other three genes displayed convincing similarities to authentic enzymes in end-toend sequence comparisons. Thus, the orf $2 *$ product is a glycosyltransferase, the Orf3* protein is a methyltransferase and orf $4^{*}$ encodes crotonyl-CoA reductase. The latter appears to be an ancillary gene, ostensibly recruited into the $t y l$ cluster to provide butyryl-CoA for polyketide metabolism. Sequence analysis of orf $3^{*}$ in $S$. fradiae GS62 (a tylM mutant defective in mycaminose metabolism), revealed an amino acid substitution in the presumed cofactor binding site of the enzyme, and reintroduction of orf $3^{*}$ into this organism resulted in restoration of tylosin biosynthesis (Gandecha et al., 1997). However, orf $2^{*}$ and its product were less easy to characterize. A tylL mutant, S. fradiae GS33 (unable to synthesize or add any of the three tylosin sugars), harbours a single mutational change (a GC to AT transition) in orf $2^{*}$ that generates an in-frame stop codon early in the coding sequence (Clark, 1997). However, attempts to restore tylosin production in this strain by complementation with fragments of tylLM DNA were inconclusive, suggesting that the TylL phenotype probably results from multiple mutations. We therefore generated a strain of $S$. fradiae specifically disrupted in orf $2 *$ in a further attempt to characterize the action of Orf $2 \%$. Unexpectedly, polyketide metabolism was also affected in this strain. 


\section{METHODS}

Bacterial strains and plasmids. S. fradiae T59235 (also known as C373.1; referred to here as wild-type) and derivatives thereof were routinely grown at $30^{\circ} \mathrm{C}$ in Tryptic Soy Broth (TSB; Difco) or at $37^{\circ} \mathrm{C}$ on AS-1 agar plates (Baltz, 1980) and were maintained at $-70^{\circ} \mathrm{C}$ as mycelial fragments following addition of $5 \%(\mathrm{v} / \mathrm{v})$ DMSO (final concn) to TSB-grown cultures. $t y l$ DNA (11 kb) from $S$. fradiae was initially excised from cosmid pMOMT4 (Beckmann et al., 1989) and introduced into pUC18 to generate pLST97 (Gandecha et al., 1997) from which an $8 \mathrm{~kb} K p n \mathrm{I}-B a m H \mathrm{H}$ fragment spanning the tylLM loci was excised and subcloned, again in pUC18, to generate pLST97A. This contained tyl orfs $1^{*}-4^{*}$ plus $t$ trD and the terminal portion of $t y l G$ (see Fig. 3). pUC-derived plasmids were manipulated in Escherichia coli using standard protocols (Sambrook et al., 1989).

Construction of disrupted orf2*. PCR-amplified orf 2 * $(1.4 \mathrm{~kb})$, with engineered terminal $\mathrm{Bam} \mathrm{HI}$ and Pst $\mathrm{I}$ sites, was generated using the following primers: $5^{\prime}$ GGATCCGTGCGTCGTGCACTGGATGAC $3^{\prime}$ and $5^{\prime}$ CTGCAGCTACCTTTCCGGCGCGGATCG 3'. Reaction mixtures $(50 \mu \mathrm{l})$ were specifically designed for $\mathrm{G}+\mathrm{C}$-rich DNA templates and contained $50 \mathrm{ng}$ template (pLST97A), $250 \mathrm{ng}$ each primer, $1 \mathrm{mM}$ dNTPs and $1 \mathrm{U}$ Taq DNA polymerase in buffer containing $60 \mathrm{mM}$ Tris $/ \mathrm{HCl}, \mathrm{pH} 8.5$ (adjusted at $20^{\circ} \mathrm{C}$ ),

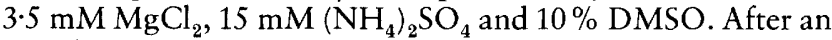
initial hot start at $80^{\circ} \mathrm{C}$ for $5 \mathrm{~min}$, the mixture was subjected to 35 cycles of amplification, each consisting of $1 \mathrm{~min}$ at $94^{\circ} \mathrm{C}$, $2 \mathrm{~min}$ at $60^{\circ} \mathrm{C}$ and $3 \mathrm{~min}$ at $72^{\circ} \mathrm{C}$, before the thermal cycle was terminated with $7 \mathrm{~min}$ at $72^{\circ} \mathrm{C}$. The PCR product was captured in pGEM-T (Promega) and introduced into E. coli NM522 (Gough \& Murray, 1983). orf2* was excised from the plasmid using the terminal BamHI and PstI sites, ligated into the respective sites in pRSET A (Invitrogen) and disrupted at the unique (and slightly off-centre) Aat II site by insertion of the $2.3 \mathrm{~kb}$ hygromycin-resistance cassette, $\Omega$ hyg (BlondeletRoualt et al., 1997). This involved blunt-end ligation using the Boehringer Mannheim Rapid DNA Ligation Kit following treatment of linearized plasmid with mung bean nuclease (Promega). Disrupted orf $*(3.7 \mathrm{~kb})$ was then removed by digestion with NheI and PstI and ligated into pOJ260, which cannot replicate in actinomycetes (Bierman et al., 1992). The resultant plasmid (pLST9734) was initially propagated in $E$. coli NM522, before being introduced into E. coli S17-1, the donor strain used for conjugal transfer to Streptomyces spp. (modified from Bierman et al., 1992; Mazodier et al., 1989).

Targeted disruption of orf2* in S. fradiae. Following growth of $S$. fradiae C 373.1 on AS- 1 medium at $37^{\circ} \mathrm{C}$ for $3 \mathrm{~d}$, spores from one plate were resuspended in $10 \mathrm{ml}$ pre-germination medium (Hopwood et al., 1985) and incubated at $37^{\circ} \mathrm{C}$ for $3-4 \mathrm{~h}$ before centrifugation and resuspension in $500 \mu \mathrm{l} \mathrm{LB}$ broth. An overnight culture $(5 \mathrm{ml})$ of $E$. coli S17-1 (containing pLST9734) grown in LB medium containing spectinomycin ( $30 \mu \mathrm{g} \mathrm{ml}^{-1}$; Sigma) and apramycin $\left(25 \mu \mathrm{g} \mathrm{ml}^{-1}\right.$; Lilly Research Laboratories) was harvested and resuspended in $500 \mu \mathrm{LB}$ medium. Then $200 \mu \mathrm{l}$ of the germinating spore suspension was mixed with $100 \mu \mathrm{l}$ of the E. coli donor cells, plated onto AS-1 agar and incubated at $37^{\circ} \mathrm{C}$. After $18 \mathrm{~h}$, the plate was overlaid with $4 \mathrm{ml}$ soft R2 agar (Hopwood et al., 1985) containing hygromycin B (100 $\mu \mathrm{g} \mathrm{ml}^{-1}$; Calbiochem) to select for transconjugants and nalidixic acid $\left(60 \mu \mathrm{g} \mathrm{ml}^{-1}\right.$; Sigma), to inhibit donor cell growth, and incubation was continued at $37^{\circ} \mathrm{C}$ for $7 \mathrm{~d}$ or until colonies had grown through the overlay. Colonies were picked and dually inoculated onto AS-1 medium containing hygromycin B $\left(100 \mu \mathrm{g} \mathrm{ml}^{-1}\right)$ or apramycin $\left(25 \mu \mathrm{g} \mathrm{ml}^{-1}\right)$ to screen for recombinants containing double cross-overs in which chromosomal orf 2 * had been replaced with the disrupted gene. Such strains were expected to be hygromycinresistant and apramycin-sensitive. Southern blot hybridization analysis was used to confirm the gene replacement and one such strain, SF01, was chosen for further analysis.

Complementation of strain SF01 with PCR-amplified orf2*. PCR-amplified orf $2 *$ was ligated into the BamHI site of pLST9829, a low-copy-number replicating plasmid (A. R. Butler \& E. Cundliffe, unpublished), downstream of the strong, constitutive promoter ermEp* (Bibb et al., 1994). The resultant plasmid, pLST9735, was then introduced into $S$. fradiae SF01 by conjugal transfer from E. coli S17-1, thereby generating strain SF02.

Tylosin-production fermentation. Conical flasks $(100 \mathrm{ml}$ capacity) containing $25 \mathrm{ml}$ pre-fermentation medium were inoculated with $100 \mu \mathrm{l} S$. fradiae stock mycelial fragments and incubated at $28^{\circ} \mathrm{C}$ with rotary shaking at 300 r.p.m. for $3 \mathrm{~d}$ (wild-type and strain SF01) or $5 \mathrm{~d}$ (strain SF02, grown in the presence of apramycin, see below). Pre-fermentation medium ( $\mathrm{pH}$ adjusted to $7 \cdot 8$ with $\mathrm{NaOH}$ ) contained $1 \%(\mathrm{w} / \mathrm{v})$ corn steep liquor, $0.5 \%(\mathrm{w} / \mathrm{v})$ yeast extract, $0.5 \%(\mathrm{w} / \mathrm{v})$ soya bean meal, $0.3 \%(\mathrm{w} / \mathrm{v})$ calcium carbonate and $0.5 \%(\mathrm{v} / \mathrm{v})$ methyl oleate. Then $5 \mathrm{ml}$ portions of each culture were used to inoculate $45 \mathrm{ml}$ batches of MM-1 tylosin production medium (Gray \& Bhuwapathanapun, 1980) and incubation was continued under similar conditions for a further $7 \mathrm{~d}$. [To maintain pLST9735 in strain SF02, apramycin $\left(25 \mu \mathrm{g} \mathrm{ml}^{-1}\right)$ was added to batches of pre-fermentation medium and tylosin production medium used for this strain.] Fermentation products were extracted by shaking the entire culture with an equal volume of chloroform, the extracts were dried by rotary flash evaporation at $30^{\circ} \mathrm{C}$ and the residues re-dissolved in $500 \mu \mathrm{l} \mathrm{HPLC}$ grade chloroform.

Analysis of fermentation products. This was done by reverse phase HPLC (as described by Huber et al., 1990) using a $3.9 \times 300 \mathrm{~mm}$ C18 $\mu$ Bondapak column protected by a C18 $\mu$ Bondapak guard column (Waters Associates). Chloroform extracts were applied to the column in $0.3 \%(\mathrm{w} / \mathrm{v})$ ammonium formate ( $\mathrm{pH} 4.0)$ containing $50 \%(\mathrm{v} / \mathrm{v})$ methanol and products were eluted using a similar buffer with a linear concentration gradient $(50-80 \%)$ of methanol at a flow rate of $1.75 \mathrm{ml} \mathrm{min}^{-1}$. The absorbance of the eluate was monitored at $282 \mathrm{~nm}$.

Bioconversion of tylosin precursors by $S$. fradiae SF01. O-Mycaminosyl-tylonolide (OMT), demycinosyl-tylosin (DMT), demycarosyl-tylosin (desmycosin) and tylosin (10 mg each) were added separately to fermentation cultures $(50 \mathrm{ml})$ in $\mathrm{MM}-1$ medium after $2 \mathrm{~d}$ at $28^{\circ} \mathrm{C}$ and incubation was continued for a further $3 \mathrm{~d}$ prior to extraction with chloroform and HPLC analysis of the products, as above.

\section{RESULTS AND DISCUSSION}

\section{The glycosyltransferase sequence motif}

When orf $2 *$ was first sequenced, its deduced product was suggested to be a glycosyltransferase (Gandecha et al., 1997). It displayed end-to-end similarity to the deduced sequences of the Mgt protein from S. lividans (Jenkins \& Cundliffe, 1991) and RhlB from Pseudomonas aeruginosa (Ochsner et al., 1994), both of which are authentic glycosyltransferases. More recently, another related protein, GtfB from glycopeptide-pro- 


\section{TyIM2 LLPTCSAVVHHGGAGTCFTATLNGLPQIVVA \\ EryCIII/Orf8 LLPTCAATVHHGGPGSWHTAAIHGVPQVILP \\ DnrS VLPSCAAVVHHGGAGTWATAALHGVPQLALA \\ DaUH LLPSCSGIIHHGGSGTFMTALAHATPQLIVP \\ RhIB LLPSCAGLVHPGGIGAMSLALAAGVPQVLLP \\ GtfB LFGRVAAVIHHGGAGTTHVARAGAPQILLP \\ Consensus LLP*CAAhhHHGGAGT $*$ *hAhh $*$ GhPQhhhP}

Fig. 4. The glycosyltransferase consensus sequence motif. Sequences: TylM2 from S. fradiae (Gandecha et al., 1997; GenBank accession no. X81885); EryCIII/Orf8 from Saccharopolyspora erythraea (Haydock, 1992); DnrS from S. peucetius (Otten et al., 1995; L47164); DauH from Streptomyces sp. strain C5 (Dickens et al., 1996; U43704); RhlB from $P$. aeruginosa (Ochsner et al., 1994; L28170); GtfB from Amycolatopsis orientalis (Solenberg et al., 1997; U84349). ' $h$ ' denotes a hydrophobic residue.

ducing Amycolatopsis orientalis, displayed glucosyltransferase activity with a glycopeptide-aglycone as acceptor substrate (Solenberg et al., 1997). Other entries in the protein identification databases were also found in routine searches using the Orf2* sequence, including DnrS and DauH from daunorubicin (daunomycin)producing S. peucetius (Otten et al., 1995) and Streptomyces sp. strain C5 (Dickens et al., 1996), respectively, but the closest match ( $50 \%$ identity) was found with the product of eryCIII (orf8) from the erythromycin producer, Saccharopolyspora erythraea (Haydock, 1992). These proteins all contain a consensus sequence motif (Fig. 4) that is also present in eukaryotic enzymes and appears to be diagnostic of a sub-group of glycosyltransferases (Cundliffe et al., 1997), although it is not present in all such enzymes. This sequence motif has been used to design (by reverse genetics) deoxyoligonucleotides that find specific hybridization targets in the genomes of antibiotic-producing Streptomyces spp. (A. R. Gandecha \& E. Cundliffe, unpublished data). The location of orf $2^{*}$ within the tylosin biosynthetic $(t y l)$ gene cluster of $S$. fradiae suggested that it probably encoded one of the three glycosyltransferase activities involved in tylosin production. This hypothesis was addressed by a combination of gene disruption and bioconversion studies.

\section{Targeted disruption of orf2* via gene replacement}

Initially, orf $2^{*}$ was amplified by PCR from wild-type $t y l$ DNA and disrupted by insertion of the hygromycin B-resistance cassette, $\Omega$ hyg (Blondelet-Roualt et al., 1997). The disrupted orf $2 *$ was then ligated into pOJ260, a suicide vector unable to replicate in actinomycetes (Bierman et al., 1992), and introduced into $S$. fradiae via conjugal transfer from E. coli S17-1. Hygromycin B-resistant transconjugants that lacked the apramycin-resistance gene of pOJ260 were selected phenotypically and Southern blot hybridization analysis (data not shown) confirmed that one such strain (designated SF01) had undergone double recombination, resulting in replacement of chromosomal orf $2^{*}$ by the disrupted gene. Thus, using orf $2 *$ as probe, the hybridization target in AflIII digests of the SF01 genome was increased in size compared with that in the wildtype $(6.9$ vs $4.6 \mathrm{~kb})$ and was also found by an $\Omega$ hyg probe. However, strain SF01 had lost the remainder of pOJ260, including the apramycin-resistance gene. In negative controls, genomic DNA from $S$. fradiae wildtype did not light up with the $\Omega$ hyg probe or with the apramycin resistance gene.

\section{Fermentation and bioconversion analysis}

The fermentation products of $S$. fradiae wild-type and strain SF01 were compared by reverse phase HPLC, following $7 \mathrm{~d}$ incubation at $28^{\circ} \mathrm{C}$ in tylosin production medium. As expected, the wild-type produced tylosin (Fig. 5a) but, surprisingly, strain SF01 produced very little material that absorbed at $282 \mathrm{~nm}$ (Fig. 5b) although traces of tylactone could be detected when the sensitivity of analysis was increased 100-fold (data not shown). In contrast, no glycosylated precursors of tylosin were evident. However, when glycosylated macrolides were fed to strain SF01 during similar fermentations, OMT was converted to tylosin (Fig. 5d), as were DMT and desmycosin, revealing that strain SF01 still possesses the deoxyallosyl- and mycarosyl-transferase activities normally associated with tylosin biosynthesis. When PCRamplified orf $2 \%$, governed by the strong, constitutive ermEp* promoter (Bibb et al., 1994), was re-introduced into strain SF01 using pLST9735 to generate strain SF02, tylosin production was restored but only at about $10 \%$ of the wild-type level (Fig. 5f).

In rationalizing these results, we considered the proposition that orf $2 *$ encodes a glycosyltransferase to be secure. The level of similarity between its deduced product and authentic glycosyltransferases, such as the GtfB protein, renders other possibilities remote. Since mycaminose is normally the first sugar to be added to the polyketide aglycone during tylosin production and since glycosylated macrolide(s) are not produced by the orf $2^{*}$-disrupted strain, SF01, we conclude that orf $2 *$ encodes the mycaminosyl-transferase enzyme. Accordingly, orf $2^{*}$ has been designated tylM2 since it is located at, or very close to, the mycaminose-specific $t y l M$ locus in the genome of $S$. fradiae (Beckmann et al., 1989; Fishman et al., 1987). Why then does strain SF01 not accumulate significant levels of tylactone? Is tylactone unstable in S. fradiae when not glycosylated, or is polyketide metabolism impaired in strain SF01?

\section{Polyketide metabolism and glycosylation}

These results call to mind earlier observations with the tylM mutant, GS62, in which orf ${ }^{*}$ has recently been shown to be altered (Gandecha et al., 1997). This gene encodes methyltransferase activity normally involved in mycaminose biosynthesis (and is therefore designated $t y l M 1$ ), yet strain GS62 (like SF01) accumu- 

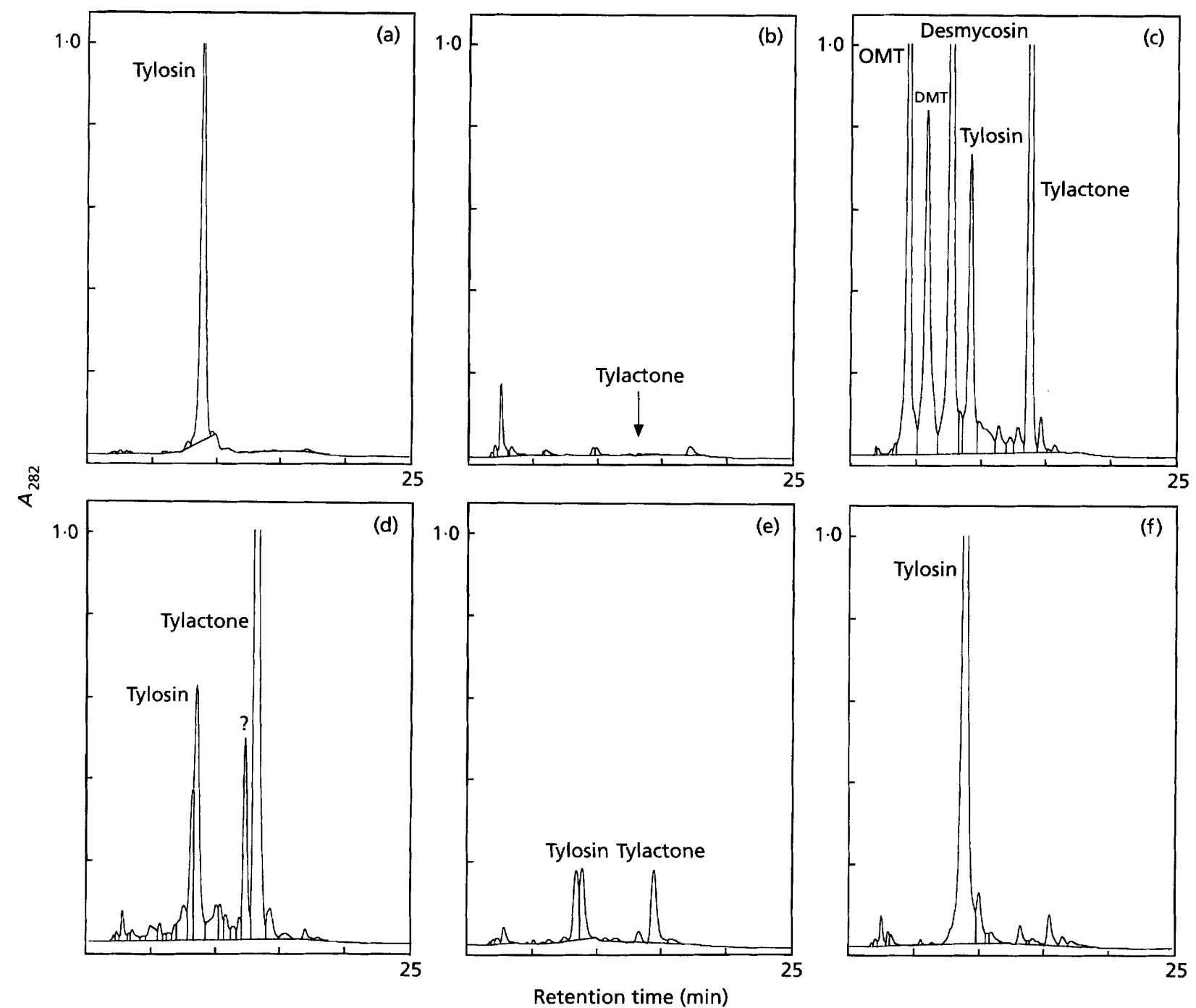

Fig. 5. HPLC analysis of S. fradiae fermentation products produced by (a) S. fradiae wild-type, (b) strain SF01, (d, e) strain SF01 with exogenously added OMT (d) or tylosin (e) and ( $f$ ) strain SF02. (c) Standard compounds (50 $\mu \mathrm{g}$ each). Relomycin (20-dihydrotylosin) is co-produced with tylosin in S. fradiae and appears as a leading shoulder on the tylosin absorption peak. Relative to the total amounts of fermentation product(s) obtained, the proportionate loading in (a) was $10 \%$ of that in (b), (d), (e) and (f).

lated only trace amounts of tylactone, together with fatty acids of intermediate chain length that appeared to be precursors of tylactone rather than degradation products (Huber et al., 1990). Similar products were also seen with other $S$. fradiae mutants, including a $t y l B$ mutant (blocked in mycaminose biosynthesis) and tylA and tylL mutants (blocked in the biosynthesis or addition of all three tylosin sugars), but strains blocked beyond OMT in the tylosin biosynthetic pathway (see Fig. 2) accumulated the expected glycosylated intermediates. Those results (Huber et al., 1990) and the present data suggest that polyketide metabolism in $S$. fradiae is impaired when the primary product, tylactone, cannot be glycosylated. Interestingly, tylactone did accumulate (together with unidentified material eluting slightly earlier during HPLC) in strain SF01 when tylosin or its glycosylated precursors were added to fermen- tations. This effect (Fig. 5d) was seen most prominently with OMT, and also with DMT or desmycosin (for structures, see Fig. 2), whereas, of the four compounds tested, tylosin was by far the least active in this respect (Fig. 5e). Since tylactone could not have been formed by degradation of the added compounds (unless, as seems unlikely, lactone ring hydroxylation could be reversed), polyketide metabolism appears to have been stimulated in the presence of the glycosylated macrolides.

Superimposed on such considerations is the possibility that disruption of orf $2^{*}$ in strain SF01 might have exerted a polar effect on the expression of downstream genes, particularly orf 4* (ccr) which encodes crotonylCoA reductase. This enzyme has been proposed (Gandecha et al., 1997) to participate in the conversion of acetoacetyl-CoA to butyryl-CoA, the extender unit 
that provides carbons 5, 6,19 and 20 of tylactone during polyketide metabolism, although other (perhaps less productive) routes to butyryl-CoA are not excluded. Whether the failure of strain SF01 to accumulate tylactone and/or the low level of tylosin production by strain SF02 are due to impaired expression of $c c r$ may become clear when transcripts have been mapped and promoters located within the orf $1^{*}-4^{*}$ region. It is also possible that the performance of strain SF02 may have been adversely influenced by the state of the PCRamplified orf $2 *$ construct, which was not sequenced. Studies are in hand to assess these various possibilities together with the likely contributions of genetic regulatory elements to the control of polyketide and/or deoxyhexose metabolism in $S$. fradiae.

\section{ACKNOWLEDGEMENTS}

This work was supported by The Wellcome Trust (grant number 036679). We thank Dr Eugene T. Seno (Lilly Research Laboratories, Indianapolis, IN) for providing $S$. fradiae T59235 and cosmid pMOMT4; Dr Philipe Mazodier (Institut Pasteur, Paris) for E. coli S17-1; and Dr Herbert A. Kirst (Lilly Research Laboratories, Greenfield, IN) for samples of tylosin, OMT, DMT and desmycosin.

\section{REFERENCES}

Baltz, R. H. (1980). Genetic recombination by protoplast fusion in Streptomyces. Dev Ind Microbiol 21, 43-54.

Baltz, R. H. \& Seno, E. T. (1981). Properties of Streptomyces fradiae mutants blocked in biosynthesis of the macrolide antibiotic tylosin. Antimicrob Agents Chemother 20, 214-225.

Baltz, R. H., Seno, E. T., Stonesifer, J. \& Wild, G. M. (1983). Biosynthesis of the macrolide antibiotic tylosin. A preferred pathway from tylactone to tylosin. J Antibiot 36, 131-141.

Beckmann, R. J., Cox, K. \& Seno, E. T. (1989). A cluster of tylosin biosynthetic genes is interrupted by a structurally unstable segment containing four repeated sequences. In Genetics and Molecular Biology of Industrial Microorganisms, pp. 176-186. Edited by C. L. Hershberger, S. W. Queener \& G. Hegeman. Washington, DC: American Society for Microbiology.

Bibb, M. J., White, J., Ward, J. M. \& Janssen, G. R. (1994). The mRNA for the $23 \mathrm{~S}$ rRNA methylase encoded by the ermE gene of Saccharopolyspora erythraea is translated in the absence of a conventional ribosome-binding site. Mol Microbiol 14, 533-545.

Bierman, M., Logan, R., O’Brien, K., Seno, E. T., Rao, R. N. \& Schoner, B. E. (1992). Plasmid cloning vectors for the conjugal transfer of DNA from Escherichia coli to Streptomyces spp. Gene 116, 43-49.

Blondelet-Roualt, M. H., Weiser, J., Lebrihi, A., Branny, P. \& Pernodet, J.-L. (1997). Antibiotic resistance gene cassettes derived from the $\Omega$ interposon for use in E. coli and Streptomyces. Gene 190, 315-317.

Clark, S. L. (1997). Analysis of the tylLM region of the Streptomyces fradiae chromosome. $\mathrm{PhD}$ thesis, University of Leicester.
Cundliffe, E., Fish, S. A., Wilson, V. T. W., Gandecha, A. R. \& Large, S. L. (1997). Glycosyl transfer during tylosin production in Streptomyces fradiae. In Genetics and Molecular Biology of Industrial Microorganisms, pp. 176-186. Edited by R. H. Baltz, G. D. Hegeman \& P. L. Skatrud. Fairfax, VA: Society for Industrial Microbiology.

Dickens, M. L., Ye, J. \& Strohl, W. R. (1996). Cloning, sequencing, and analysis of aklaviketone reductase from Streptomyces sp. strain C5. J Bacteriol 178, 3384-3388.

Fishman, S. E., Cox, K., Larson, J. L., Reynolds, P. A., Seno, E. T., Yeh, W.-K., Van Frank, R. \& Hershberger, C. L. (1987). Cloning genes for the biosynthesis of a macrolide antibiotic. Proc Natl Acad Sci USA 84, 8248-8252.

Gandecha, A. R., Large, S. L. \& Cundliffe, E. (1997). Analysis of four tylosin biosynthetic genes from the tylLM region of the Streptomyces fradiae genome. Gene 84, 197-203.

Gough, J. A. \& Murray, N. E. (1983). Sequence diversity among related genes for recognition of specific targets in DNA molecules. J Mol Biol 166, 1-19.

Gray, P. P. \& Bhuwapathanapun, S. (1980). Production of the macrolide antibiotic tylosin in batch and chemostat culture. Biotechnol Bioeng 22, 1785-1804.

Haydock, S. F. (1992). Studies on the erythromycin biosynthetic gene cluster. PhD thesis, University of Cambridge.

Hopwood, D. A., Bibb, M. J., Chater, K. F., Kieser, T., Bruton, C. J., Kieser, H., Lydiate, D. J., Smith, C. P., Ward, J. M. \& Schrempf, H. (1985). Genetic Manipulation of Streptomyces : a Laboratory Manual. Norwich: John Innes Foundation.

Huber, M. L. B., Paschal, J. W., Leeds, J. P., Kirst, H. A., Wind, J. A., Miller, F. D. \& Turner, J. R. (1990). Branched-chain fatty acids produced by mutants of Streptomyces fradiae, putative precursors of the lactone ring of tylosin. Antimicrob Agents Chemother 34, 1535-1541.

Jenkins, G. \& Cundliffe, E. (1991). Cloning and characterisation of two inducible genes from Streptomyces lividans, responsible for resistance to lincomycin and macrolide antibiotics. Gene 108, $55-62$.

Mazodier, P., Petter, R. \& Thompson, C. (1989). Intergeneric conjugation between Escherichia coli and Streptomyces species. J Bacteriol 171, 3583-3585.

Ochsner, U. A., Fiechter, A. \& Reiser, J. (1994). Isolation, characterization, and expression in Escherichia coli of the Pseudomonas aeruginosa $r$ blAB genes encoding a rhamnosyltransferase involved in rhamnolipid biosurfactant synthesis. $J$ Biol Chem 269, 19787-19795.

Otten, S. L., Liu, X., Ferguson, J. \& Hutchinson, C. R. (1995). Cloning and characterization of the Streptomyces peucetius $d n r Q S$ genes encoding a daunosamine biosynthesis enzyme and a glycosyl transferase involved in daunorubicin biosynthesis. $J$ Bacteriol 177, 6688-6692.

Sambrook, J., Fritsch, E. F. \& Maniatis, T. (1989). Molecular Cloning : a Laboratory Manual, 2nd edn. Cold Spring Harbor, NY: Cold Spring Harbor Laboratory.

Solenberg, P. J., Matsushima, P., Stack, D. R., Wilkie, S. C., Thompson, R. C. \& Baltz, R. H. (1997). Production of hybrid glycopeptide antibiotics in vitro and in Streptomyces toyocaensis. Chem Biol 4, 195-202.

Received 4 June 1997; revised 27 August 1997; accepted 5 September 1997. 